\title{
BIODIESEL PRODUCTION FROM PALM OIL USING HOMOGENEOUS CATAYST SYSTEM
}

\author{
Y.C. Wong ${ }^{1^{*}}$ and Nurfarhana S. $^{1}$
}

${ }^{1}$ Faculty of Agro Based Industry, Universiti Malaysia Kelantan, Jeli Campus, Locked Bag 100, 17600 Jeli, Kelantan, Malaysia.

\subsection{Abstract}

Due to the depletion of petroleum reserves and environmental concern, biodiesel has emerged as one of the most potential energy to replace petroleum. It is a renewable, biodegradable and non-toxic fuel which can be easily produced through transesterification.Transesterification of palm oil with methanol has been studied in a homogenous catalyst system using different catalysts $\left(\mathrm{CaCO}_{3}, \mathrm{SrCO}_{3}\right.$ and $\left.\mathrm{BaCO}_{3}\right)$. The effects of concentration catalyst $(0.25 \% \mathrm{w} / \mathrm{w}-1.5 \% \mathrm{w} / \mathrm{w})$ and molar ratio of methanol to oil (3:1-21:1) on biodiesel yield and conversion of FFA to FAME was investigated. From this study, $\mathrm{SrCO}_{3}$ gave better yields of $\mathrm{FAME}$ while $\mathrm{CaCO}_{3}$ gave better conversion of FFA to FAME. The lowest yield of FAME was recorded at catalyst concentration of $0.25 \% \mathrm{w} / \mathrm{w}$ while the highest yield of FAME was at $1.25 \% \mathrm{w} / \mathrm{w}$. The lowest conversion of FFA to FAME was at $0.25 \% \mathrm{w} / \mathrm{w}$ and the highest conversion at catalyst concentration of $0.75 \% \mathrm{w} / \mathrm{w}$. For the molar ratio of methanol to oil, the minimum yield of FAME at 21: while the maximum yield of FAME was obtained at 3:1. The minimum conversion of FFA to FAME was recorded at 3:1 molar ratio methanol to oil. However, maximum conversion was recorded at 15:1 molar ratio methanol to oil. This study revealed that biodiesel was successfully reduced $52.3 \%$ opacity level of smoke emission by diesel engine that operated with petroleum diesel.

Keywords: Palm oil; biodiesel; homogeneous catalyst system; transesterification; FFA; FAME; opacity level.

\section{Council for Innovative Research}

Peer Review Research Publishing System

\section{Journal: Journal of Advances in Chemistry}

Vol. 11, No. 10

www.cirjac.com

editorjaconline@gmail.com, editor@cirjac.com 


\subsection{Introduction}

Most countries depend on fossil fuels to generate energy including electricity which is essential for continuous development and economic growth [1]. However, The combustion of fossil fuels simultaneously creates several environmental concern which can threaten the sustainability of our ecosystem [2]. Biodiesel which is mainly derived from vegetable oils or animal fats and has shown great potential to serve as a substitute to petroleum derived diesel for compression ignition engine [3]. Besides, it commonly known to offer several advantages over fossil fuel such as sustainability, biodegradability, lower greenhouse gas emissions, regional development, social structure and agriculture development, and fuel security supply [4].

Malaysia is one of the countries which actively advocates for the commercial production and usage of biodiesel as fossil fuels replacement due to its rich palm oil resources. Palm oil is known as an important source of edible oil with significant values of renewable energy. From all of the biodiesel feedstock, palm oil is the potential candidates due to its raw materials supply and production cost [5].

Transesterification is a conventional and the most adopted process for biodiesel production [6]. Transesterification is a chemical reaction whereby triglycerides molecule present in animal fats or vegetable oils react with alcohol in the presence of a catalyst. The product of the reaction are FAME, which is biodiesel and glycerin as a byproduct. [7]. The simplified form of its chemical reaction is presented in Figure 1. Homogeneous catalyst act in the same liquid phase as the reaction mixture. Currently, homogeneous catalysts applications due to their simple usage and less time required for oil conversion dominate the biodiesel industry [8].

Methanol is one type of alcohol favored commonly used in biodiesel production due to its low cost, industrial availability and its physical and chemical properties which are polar and shortest chain alcohol [9]. The transesterification reaction also requires a catalyst to increase the reaction rate and split the oil molecules [10]. Catalyst that can be used for transesterification reaction include alkali, acid or enzyme. Catalytic transesterification may be performed using homogeneous, in the same phase as the reactants and products, and heterogeneous, in a separate phase [11].

The main objectives of this study are to study the effect of type catalyst, molar ratio of methanol to oil, concentration of catalyst on the yield of biodiesel and conversion of FFA to FAME. Besides, to determine the free fatty acid value using titration method and to compare the performance and emission of a diesel engine using palm biodiesel and petroleum diesel. The figure below shown palm oil tree (Elaeis guineensis) in Figure 2.

\subsection{Materials and method}

\subsection{Raw materials treatment}

Palm oil was collected from Elegant Palms Sdn. Bhd., Perak. The palm oil was filtered to remove any insoluble impurities and preheated at $60^{\circ} \mathrm{C}$ to remove the moisture content [12].

\subsection{FFA percentage value}

Titration method was used to determined FFA content in the palm oil[13]. $10 \mathrm{~mL}$ of isopropanol was measured into $100 \mathrm{~mL}$ of beaker and three to four drops of phenolphthalein indicator was added. It was titrated against $0.1 \mathrm{M}$ of $\mathrm{NaOH}$ until the pink color was obtained. Next, $1 \mathrm{~mL}$ of palm oil was added to the mixture and it was titrated again until the pink color was obtained.

The percentage FFA was calculated from the equation below

$\% F F A=\frac{V \times M \times W}{m}$ (Eq. 1)

Where, $\mathrm{V}=$ Volume of $\mathrm{NaOH}$ used $(\mathrm{mL})$

$\mathrm{M}=$ Molarity of the $\mathrm{NaOH}$ used $(\mathrm{mol} / 1000 \mathrm{~mL})$

$\mathrm{W}=$ Molecular weight of the fatty acid component in the palm oil $(\mathrm{g} / \mathrm{mol})$

$\mathrm{m}=$ mass of the palm oil sample $(\mathrm{g})$

\subsection{Mixing alcohol and catalyst}

The desired amount of methanol and catalyst were weighed. The catalyst was slowly and carefully poured into the methanol in the beaker. Most of the catalysts are in solid form and do not readily dissolve into methanol, it was best to start agitating the methanol in a beaker using magnetic stirrer and added the catalyst slowly and carefully. This was purpose to allow the catalyst dissolved completely in methanol and to produce methoxide which willreact with the base oil. After the catalyst completely dissolved in the methanol, the methoxide is ready to be added to the palm oil [14]. This step were repeated using different type of catalyst $(\mathrm{CaCO} 3, \mathrm{SrCO}, \mathrm{BaCO} 3)$, molar ratio of methanol to oil (3:1-21:1) and concentration of catalyst $(0.25-1.50 \% \mathrm{w} / \mathrm{w})$. 


\subsection{Transesterification and separation}

Palm oil $(35 \mathrm{~g})$ was weighed and placed it in a $100 \mathrm{~mL}$ beaker. The mixture of alcohol and catalyst were added to the preheated palm oil. A magnetic stirrer was used for mixing the oil, methanol and catalyst at fixed temperature, $55^{\circ} \mathrm{C}$, controlled stirring speed, $600 \mathrm{rpm}$ and conducted for $120 \mathrm{~min}$ to ensure the completion the conversion of the fatty acid into FAME. The reaction was stopped by cooling the beaker to room temperature. The mixture was allowed to stand overnight to ensure that the separation of the methyl esters and the glycerol phase occurred completely [15].After $12 \mathrm{~h}$ separation time, the upper phase will consist of crude biodiesel, while the lower layer contain the glycerol. The glycerine phase was removed while the crude biodiesel was retained to remove the water soluble contamination.

\subsection{Washing and purification of crude biodiesel}

The crude biodiesel was washed several times with warm distilled water until the washings were clear to prevent the precipitation of saturated fatty acid esters and retards the formulation of emulsion[16]. Few drops of acetic acid were added to neutralize any unreacted catalyst and to decompose the soap formed during the reaction. For further purification, the ester product was dried by gentle heating to obtain refined biodiesel. The volume of the washed biodiesel was measured and recorded.

\subsection{Analytical analysis}

The biodiesel yield and the conversion of FFA to FAME percentage were recorded. According to [17], yield of treated palm oil after transesterification process was calculated (Eq. 2). The conversion of FFA to FAME was calculated (Eq. 3).

$$
\text { Yield }=\frac{\text { Produced biodiesel }}{\text { Initial oil weight }} \times 100
$$

The conversion of biodiesel FFA were defined according to

$$
\text { Conversion }=\frac{\text { Nso }-\mathrm{Ns}}{\mathrm{Nso}} \times 100
$$

$$
\text { Where, Nso }=\text { FFA content at the start of reaction }
$$$$
\text { Ns = FAME content at the end of reaction }
$$

\subsection{Biodiesel smoke opacity test}

This test was observed at Department of Environment, Ministry of Natural Resources and Environment where the place has a facility to conduct diesel engine vehicle smoke emission test. Experiments were conducted in a direct injection YANMAR Diesel Engine which have four stroke, single cylinder, and 4.8 horsepower. A diesel smoke meter was used to measure the smoke opacity of the engine exhaust.

\subsection{Results and Discussion}

\subsection{Effect of catalyst type and catalyst concentration on yield of FAME}

Figure 3 showed catalyst concentration $0.25 \%$ w/w gave the lowest biodiesel yield. [18] reported that the lowest catalyst concentration gave the lowest yield of FAME because it was insufficient of catalyst to catalyze the transesterification reaction. $1.25 \% \mathrm{w} / \mathrm{w}$ gave the best yield of FAMEwhile at $1.5 \% \mathrm{w} / \mathrm{w}$, the yield of FAME were dropped. [19] have demonstrated that when the catalyst concentration is increase, it will help to fasten the transesterification reaction and gave better yield of FAME. However, when beyond the optimum value, excessive catalyst will participate in saponification which reacts with triglyceride to form soap and water. Thus, it will reduce the biodiesel yield.

\subsection{Effect of catalyst type and catalyst concentration on conversion of FFA to FAME}

Based on the Figure 4, the lowest conversion for $\mathrm{CaCO} 3$ was at $0.25 \% \mathrm{w} / \mathrm{w}$. For SrCO3 it lowest at $1.5 \% \mathrm{w} / \mathrm{w}$ while for $\mathrm{BaCO} 3$ was at $0.5 \% \mathrm{w} / \mathrm{w}$. [20] remarked that an insufficient amount of catalyst will result in an incomplete conversion of the triglycerides into fatty acid esters. The highest conversion for $\mathrm{CaCO} 3$ was recorded at $0.75 \% \mathrm{w} / \mathrm{w}$. For $\mathrm{SrCO} 3$, the highest conversion was at $0.25 \% \mathrm{w} / \mathrm{w}$ while for $\mathrm{BaCO} 3$ at $1.25 \% \mathrm{w} / \mathrm{w}$. [21] showed the higher concentration of catalyst in the methanol phase due to the higher diffusion rate of catalyst in the oil phase. Hence, it showed higher reaction rate with FFA.

\subsection{Effect of catalyst type and molar ratio methanol to oil on yield of FAME}

It can be seen generally from the Figure 5 that increasing the molar ratio methanol to oil from $3: 1$ to $21: 1$, the yield of FAME decreasing for all type of catalyst. This is due to high molar ratio of methanol to oil interferes with separation of glycerin because there is an increase in solubility. When glycerin remains in solution, it helps drive the equilibrium to back to the left and lowering the yield of esters [22].

$3: 1$ gave the highest yield of biodiesel for all type of catalyst.In transesterification, each mole of triglycerides reacts stoichiometrically with three moles of a primary alcohol and yields three moles of alkyl ester as biodiesel and one mole of 
glycerol as the byproduct. The actual mechanism of the transesterification reaction consists of sets of equilibrium reactions in series and all of the reactions are reversible [21].

\subsection{Effect of catalyst type and molar ratio methanol to oil on conversion of FFA to FAME}

From the Figure 6, it was found the lowest conversion of FFA to FAME for all type of catalyst were at molar ratio methanol to oil 3:1. [23] stated the low molar ratio will drive the reaction to the left, low in solubility and decrease the contact between the triglycerides and alcohol molecules. The highest FFA conversion to FAME for $\mathrm{CaCO} 3$ at molar ratio methanol to oil 15:1, $\mathrm{SrCO} 3$ at 12:1 while for $\mathrm{BaCO} 3$ at 21:1. Higher molar ratio methanol to oil, catalyst concentration was relatively low but the oil solubility in methanol increased [21].

\subsection{Best catalyst for yield of FAME and conversion of FFA to FAME}

$\mathrm{CaCO}_{3}$ catalyst have revealed to give better conversion of FFA to FAME due to relatively high basic strength and less environmental impacts due to its low solubility in methanol [24]. A study by [25], has also suggested that the calcium series catalysts have higher catalytic activity for the transesterification reaction.

This study also showed that $\mathrm{SrCO}_{3}$ gave better yield of $\mathrm{FAME}$ compared than $\mathrm{CaCO}_{3}$ and $\mathrm{BaCO}_{3}$. The activity of the catalysts were mainly related to their basic strength. The basicity of alkaline earth metal carbonate increase in the order $\mathrm{CaCO}_{3}<\mathrm{SrCO}_{3}<\mathrm{BaCO}_{3}$. This is because the ionic radii of alkaline earth metal increases and their electronegativity decreases in this order [26].

However, [27] remarked that the use of $\mathrm{BaCO}_{3}$ in transesterification is not practical enough since it is soluble in methanol and also forms highly toxic compounds. Therefore, these barium catalyst are not recommended to serve as catalyst for the transesterification process [28].

\subsection{Biodiesel smoke opacity test}

Based on the summarised results in Figure 7, the mean opacity percentage of smoke emission from diesel engine operated with conventional diesel was $66.2 \%$. However, mean opacity percentage for diesel engine operated with biodiesel was $31.6 \%$. Hence, this revealed that biodiesel was successfully reduced $52.3 \%$ opacity level of smoke emitted from diesel engine that operated with petroleum diesel.

According to [29], the limitation or standard smoke emitted from exhaust emission of diesel vehicle was allowed for not more than 50 Hatridge Smoke Unit (HSU) or $50 \%$ opacity level. However, in Figure 7, it reported that opacity level of smoke emission for conventional diesel was more than $50 \%$ which had exceed the standard. The smoke emission for palm biodiesel were not more than the standard smoke emission by the Department of Environmental Malaysia. Therefore, biodiesel was claimed to be safe for environment and human health.

During the test, the diesel engine was fueled with $80 \%$ of biodiesel blended with $20 \%$ of diesel (B80). The blended was done to overcome the starting difficulties and to make sure diesel engine ran satisfactorily throughout the entire test. The smoke opacity for biodiesel blended fuel was found to be lower than diesel. [30] reported that the reduction of smoke opacity of biodiesel in the fuel blend attributed to the decrease in the carbon content and the increase of oxygen content. $\mathrm{C}-\mathrm{C}$ bond in the biodiesel blended fuel was lesser compared with diesel, resulting in the decrease of smoke opacity. In addition, the oxygen in the fuel at the same time can assist in reducing smoke formation during the stage of diffusion combustion [31].

\subsection{Conclusion}

From the comparison at different concentration of catalyst and molar ratio methanol to oil, $\mathrm{SrCO} 3$ gave better yields than the $\mathrm{CaCO} 3$ and $\mathrm{BaCO} 3$. However, for the conversion of FFA to FAME, $\mathrm{CaCO} 3$ gave the better conversion compare with other type of catalyst.

Effect of concentration of catalyst on yield of FAME and conversion of FFA to FAME were investigated in this study. The highest yield was recorded at catalyst concentration $1.25 \% \mathrm{w} / \mathrm{w}$. However, for the conversion of FFA to FAME was highest at $0.75 \% \mathrm{w} / \mathrm{w}$ concentration of catalyst due to the higher diffusion rate of catalyst in the oil phase. Hence, it showed higher reaction rate with FFA.

Besides, the yield of FAME and conversion FFA to FAME were also affected by the molar ratio methanol to oil. From the study, the maximum yield FAME obtained was at 3:1 molar ratio methanol to oil. While the maximum conversion of FFA to FAME was recorded at 15:1 molar ratio methanol to oil. In the transesterification, each mole of triglycerides reacts stoichiometrically with three moles of a primary alcohol and yields three moles of alkyl ester as biodiesel and one mole of glycerol as the byproduct. However, it suggested to increase the mole of alcohol to get better result in conversion conversion.

The biodiesel smoke opacity test for diesel and biodiesel was compared in unmodified diesel engine. Biodiesel showed $52.3 \%$ reduction of opacity level in smoke emission test. Hence, biodiesel claimed can gave environmental benefits compared to petroleum diesel. The reduction is due to $\mathrm{C}-\mathrm{C}$ bond in the biodiesel blended fuel which was lesser compared with diesel, resulting in the decrease of smoke opacity. 


\section{Acknowledgement}

The authors express their sincere appreciation to Faculty of Agro Based Industry, Universiti Malaysia Kelantan, Jeli Campus for the financial support and a good facilities which made this study possible. Not to forget deepest thanks to the Department of Environment, Ministry of Natural Resources and Environment staffs who have provided the equipment and contribution of knowledge in completing this thesis.

\section{References}

[1] Kumar, N., Varun, \& Chauhan, S. R. (2013). Performance and emission characteristics of biodiesel from different origins: A review. Renewable and Sustainable Energy Reviews, 21, 633-658.

[2] Lim, S., \& Teong, L. K., (2010). Recent trends, opportunities and challenges of biodiesel in Malaysia: An overview. Renewable and Sustainable Energy Reviews, 14, 938-954.

[3] Agarwal, A. K., (2007). Biofuels (alcohols and biodiesel) applications as fuels for internal combustion engines. Progress in Energy and Combustion Science, 33, 233-71.

[4] Reijinders, L. (2006). Conditions for the sustainability of biomass based fuel use. Energy Policy, 34, 863-876.

[5] Pleanjai, S., Gheewala, S. H. \& Garivait, S. (2007). Environment evaluation of biodiesel production from palm oil a life cycle perspective. Asian Journal Energy Environment, 8, 15-32.

[6] Saeid, B., Aroua, M. K., Abdul Raman, A., Sulaiman, N. M. N. (2008). Densities of ethyl esters produced from different vegetable oils. J Chem Eng Data, 53, 2222-2225.

[7] Hameed, B. H., Lai, L. F., \& Chin, L. H. (2009). Production of biodiesel from palm oil (Elaeis guineensis) using heterogeneous catalyst: An optimized process. Fuel Processing Technology, 90, 606-610.

[8] Borges, M. E., \& Díaz, L. (2012). Recent developments on heterogeneous catalyst for biodiesel production by oil esterification and transesterification reactions: A review. Renewable and Sustainable Energy Reviews, 16, 28392849.

[9] Lam, M. K., Lee, K. T., \& Mohamed, A. R., (2010). Homogeneous, heterogeneous and enzymatic catalysis for transesterification of high free fatty acid oil (waste cooking oil) to biodiesel: A review. Biotechnology Advance, 28(4), 500-18.

[10] Hasheminejad, M., Tabatabaei, M., Mansourpanah, Y., Khatami, M., \& Javani, A. (2011). Upstream and downstream strategies to economize biodiesel production. Bioresource Technology, 102(2), 461-8.

[11] Schobert, H. H. (2013). Chemistry of fossil fuels and biofuels. USA: Cambridge Press.

[12] Alamu, O. J., Waheed, M. A., Jekayinfa, S. O. (2007). Biodiesel production from Nigerian palm kernel oil: effect of $\mathrm{KOH}$ concentration on yield. Energy for Sustainable Development, 11(3), 77-82.

[13] Viele, E. L, Chukwuma, F.O., \& Uyigue, L. (2013). Esterification of high free fatty acid crude palm kernel oil as feedstock for base-catalyzed transesterification reaction. International Journal of Application or Innovation in Engineering \& Management, 2(12), 361-365.

[14] Neha, P., Chintan, B., Pallavi, \& D., Neha, T. (2013). Use sunflower and cottonseed oil to prepare biodiesel by catalyst assisted transesterification. Research Journal of Chemical Sciences, 3(3), 42-47.

[15] Noiroj, K., Intarapong, P., Luengnaruemitchai, A., \& Jai-In, S. (2009). A comparative study of $\mathrm{KOH} / \mathrm{Al} 2 \mathrm{O} 3$ and $\mathrm{KOH} / \mathrm{NaY}$ catalyst for biodiesel production via transesterification from palm oil. Renewable Energy, 34, 1145-1150.

[16] Leung, D. Y. C., \& Guo, Y. (2006). Transesterification of neat and used frying oil: Optimization for biodiesel production. Fuel Processing Technology, 87, 883-890.

[17] Al-Hamamre, Z., \& Yamin, J. (2014). Parametric study of the alkali catalyzed transesterification of waste frying oil for biodiesel production. Energy Conversion and Management, 79, 246-254.

[18] Rashid, U., \& Anwar, F. (2008). Production of biodiesel through optimized alkaline-catalyzed transesterification of rapeseed oil. Fuel, 87, 265-273.

[19] Hossain, A. B. M. S., \& Mazen, M. A. (2010). Effects of catalyst types and concentrations on biodiesel production from waste soybean oil biomass as renewable energy and environmental recycling process. Australian Journal of Crop Science. 4(7), 550-555.

[20] Guo, Y. (2005). Alkaline-catalysed production of biodiesel fuel from virgin canola oil and recycled waste oils. Phd dissertation, Department of Mechanical Engineering, University of Hong Kong, 184.

[21] Singh, A., He, B., Thompson, J., \& Van Garpen, J. (2006). Process optimization of biodiesel production using alkaline catalysts. Applied Engineering in Agriculture, 22(4), 596-600. 
[22] Murugesan, A., Umarani, C., Chinnusamy, T.R., Krishnan, M., Subramaniam, R., Neduzchezhain, N. (2009). Production and analysis of biodiesel from non-edible oils: A review. Renewable and Sustainable Energy Reviews, 13, 825-834

[23] Kumar, G., Kumar, D., Singh, S., Kothari, S., Bhatt, S., \& Singh, C. P. (2010). Continuous low cost transesterification process for the production of coconut biodiesel. Energies, 3, 43-56.

[24] Zabeti, M., Wan Daud, W. M. \& Aroua, K. (2009). Activity of solid catalyst for biodiesel production: A review. Fuel Processing Technology, 90(6), 770-777.

[25] Kawashima, A., Matsubara, K. \& Honda, K. (2008). Development of heterogeneous base catalysts for biodiesel production. Bioresource Technology, 99(9), 3439-3443.

[26] Gryglewicz, S. (1999). Rapeseed oil methyl esters preparation using heterogeneous catalyst. Bioresource Technology, 70, 249-253.

[27] Refaat, A. A., El-Sheltawy, S. T. \& Sadek, K. U. (2010). Optimum reaction time, performance and exhaust emissions of biodiesel produced by microwave irradiation. International Journal of Environmental Science and Technology, 5(3), 315-322.

[28] Department of Environment Malaysia. (2013). Control emission from diesel engines. Retrieved from www.nre.gov.my/ms-my.

[29] Gumus, M., Sayin, C. \& Canakci. M. (2012). The impact of fuel injection pressure on the exhaust emissions of a direct injection diesel engine fueled with biodiesel-diesel fuel blends. Fuel, 95, 486-494.

[30] Di, Y., Cheung, C. S., Huang, Z. (2009). Experimental investigation on regulated and unregulated emission of a diesel engine fueled with ultra-low sulfur diesel fuel blended from waste cooking oil. Sci Total Environ, 407, 835-846.

\section{LIST OF FIGURES}

Figure 1 Palm oil tree (Elaeis guineensis)

Figure 2 Chemical reaction equation in transesterification

Figure 3 The graph showed the average yield percentage of FAME against the concentration of catalyst for all type of catalyst

Figure 4 The graph showed the average conversion percentage of FFA to FAME against the concentration of catalyst for all type of catalyst

Figure 5 The graph showed the average yield percentage FAME against the molar ratio methanol to oil for all type of catalyst

Figure 6 The graph showed the average conversion percentage of FFA to FAME against the molar ratio methanol to oil for all type of catalyst

Figure 7 The graph showed comparison of opacity level of exhaust smoke which emitted from diesel engine that operated with diesel engine and biodiesel

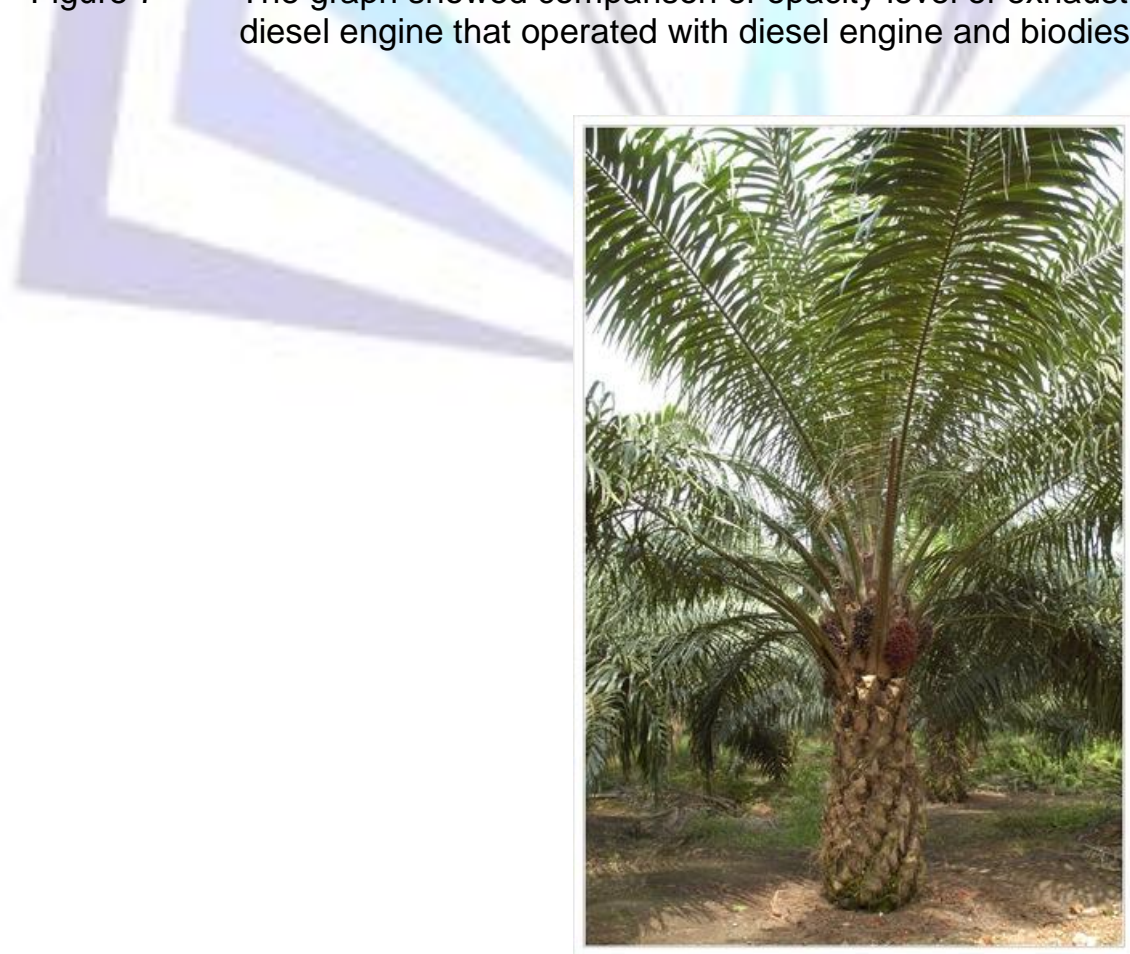

Figure 1: Palm oil tree (Elaeis guineensis) 


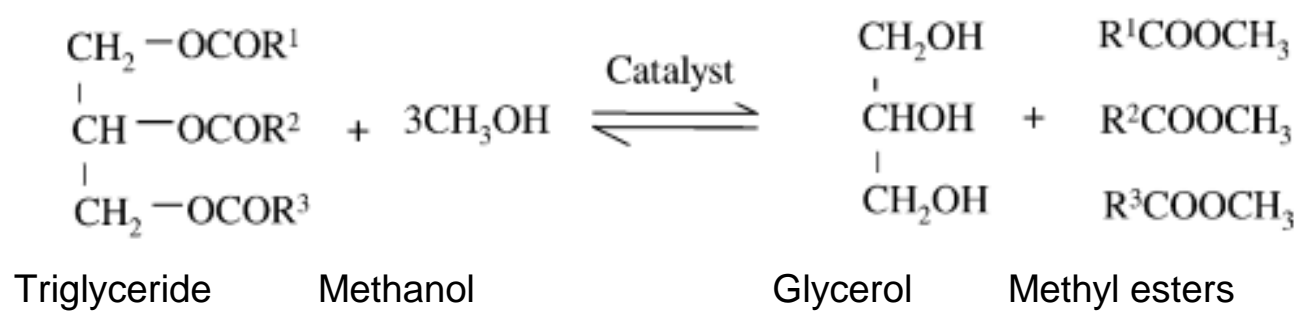

Figure 2: Chemical reaction equation in transesterification

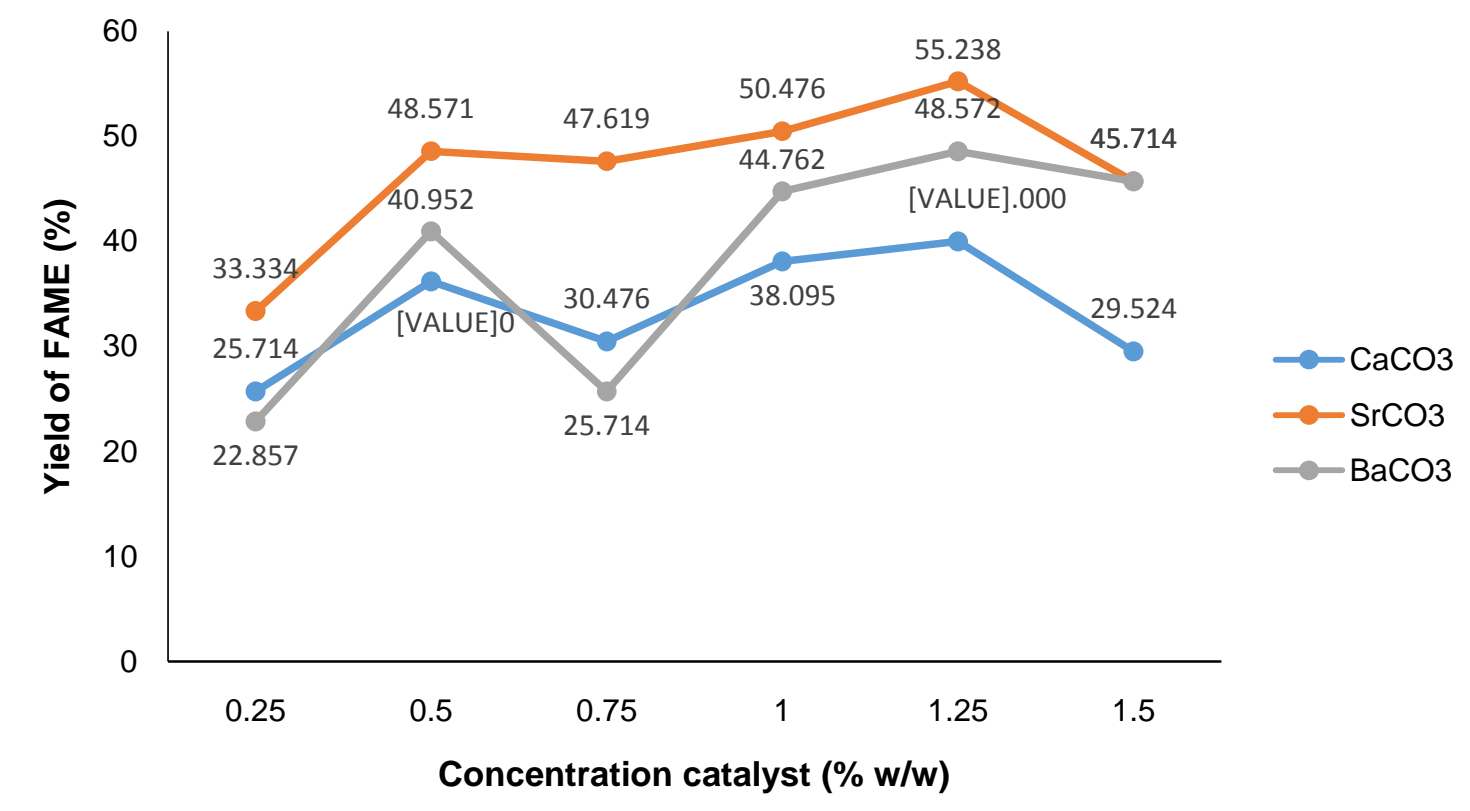

Figure 3: The graph showed the average yield percentage of FAME against the concentration of catalyst for all type of catalyst

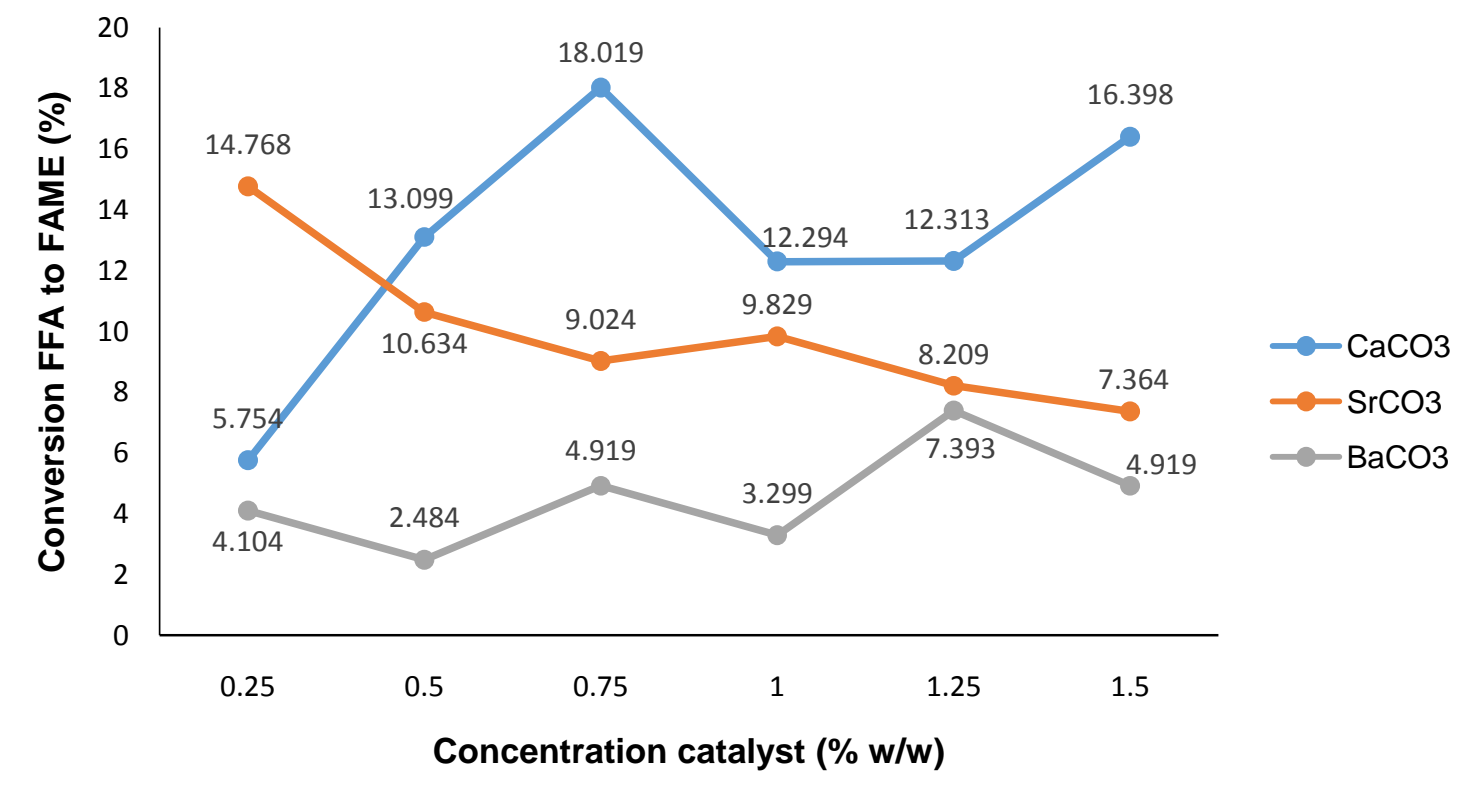

Figure 4: The graph showed the average conversion percentage of FFA to FAME against the concentration of catalyst for all type of catalyst 


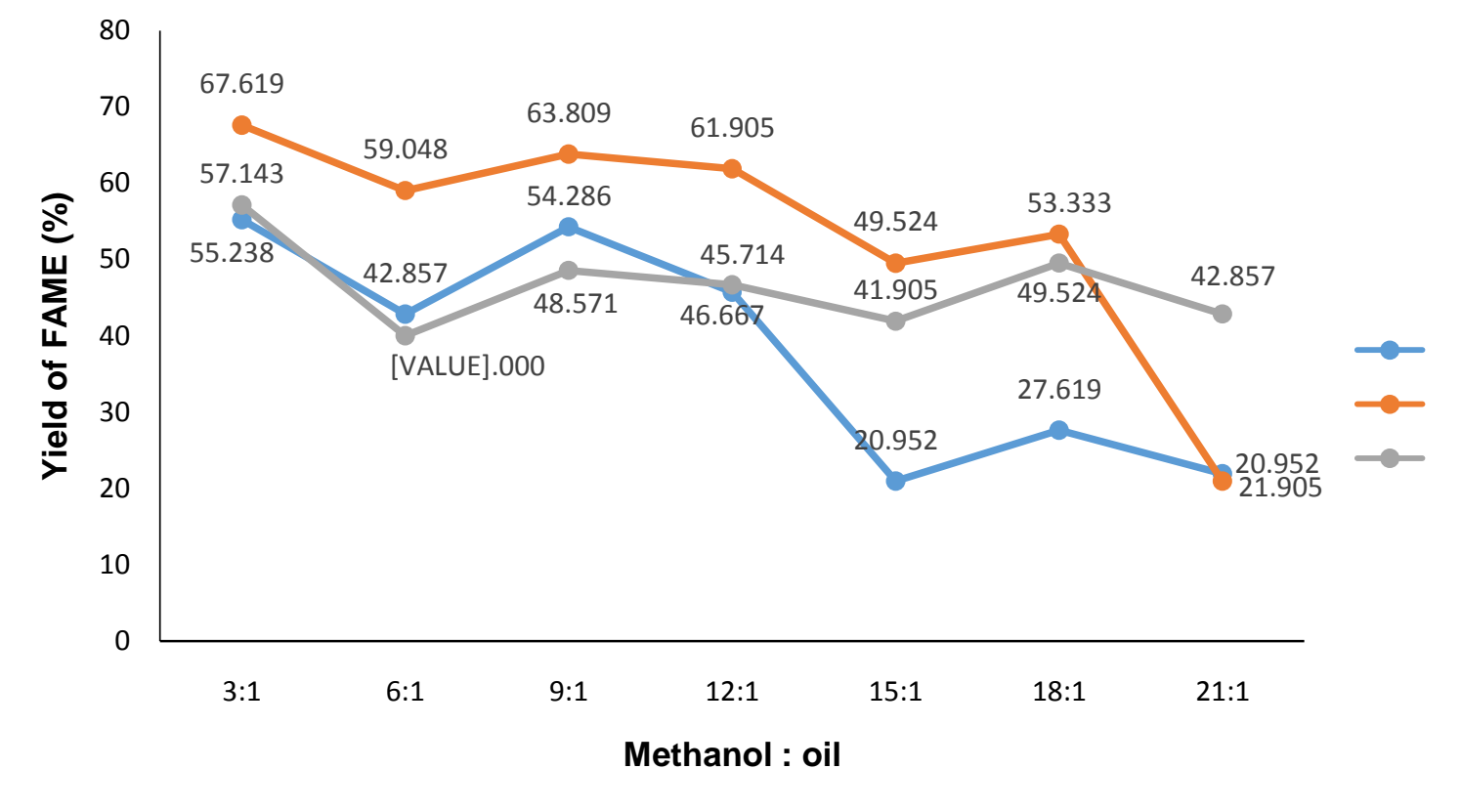

Figure 5: The graph showed the average yield percentage FAME against the molar ratio methanol to oil for all type of catalyst

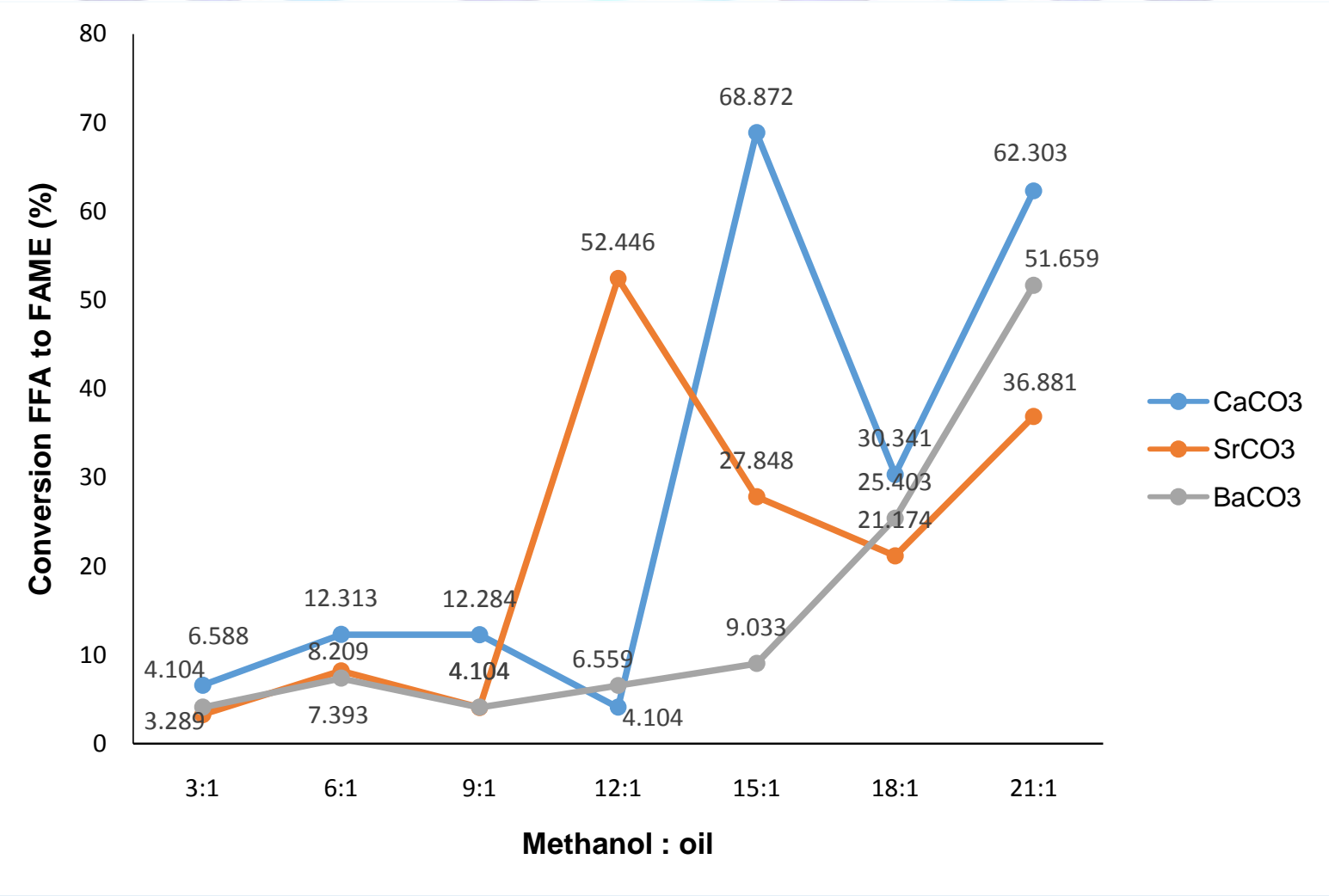

Figure 6: The graph showed the average conversion percentage of FFA to FAME against the molar ratio methanol to oil for all type of catalyst 


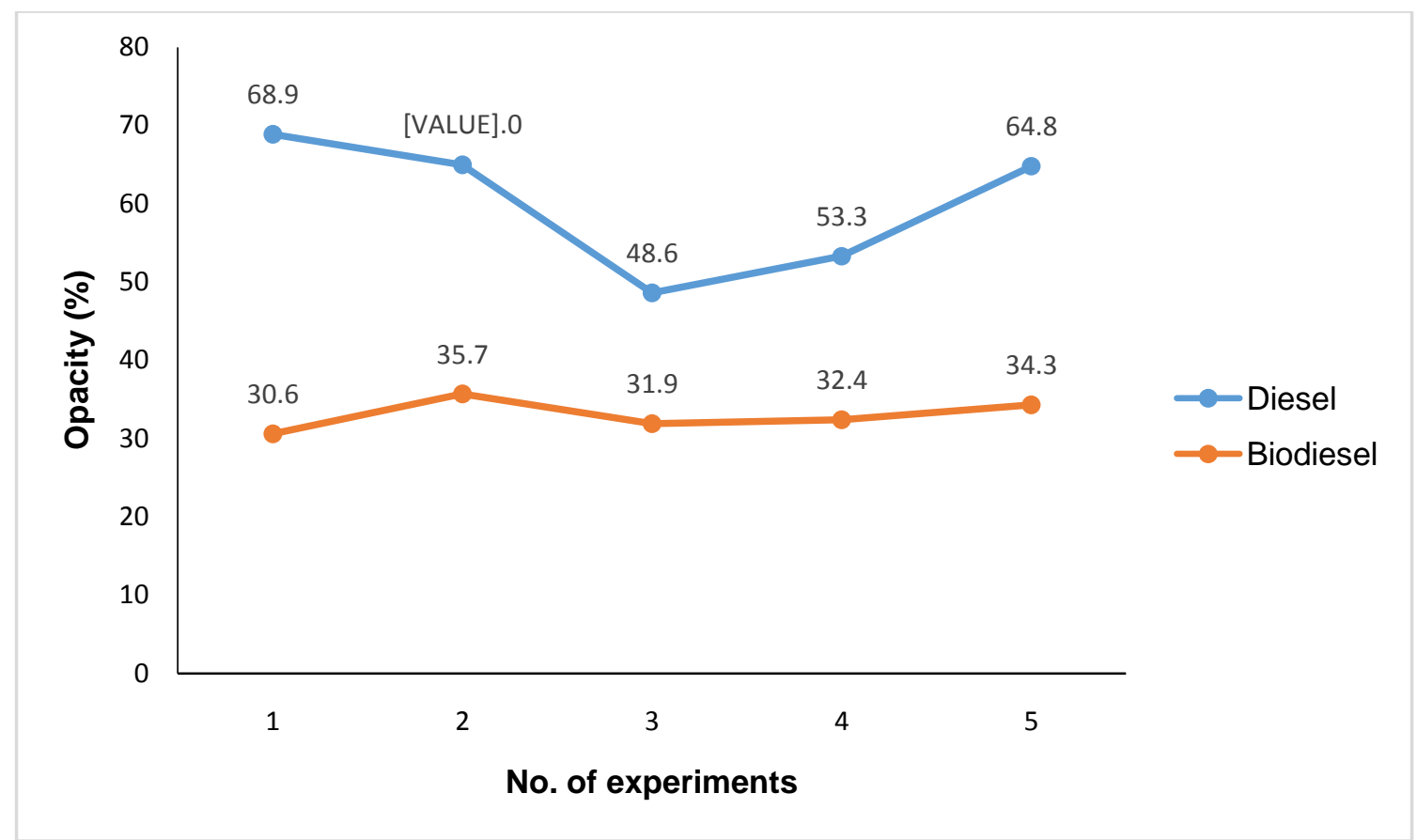

Figure 7: The graph showed comparison of opacity level of exhaust smoke which emitted from diesel engine that operated with diesel engine and biodiesel 